\title{
Corrosion of Zine
}

\author{
Effect of $\mathrm{pH}$
}

TOR HURLEN

Central Institute for Industrial Research, Blindern, Oslo, Norway

The corrosion rate $\left(i_{\mathrm{c}}\right)$ and corrosion potential $\left(E_{\mathrm{c}}\right)$ of zinc in acid chloride solutions of high chloride content ( $3 \mathrm{M})$ are found to vary with the $\mathrm{pH}$ according to:

$$
\begin{aligned}
& \text { d } \log i_{\mathrm{c}} / \mathrm{d} \mathrm{pH}=-4 / 5 \\
& \text { d } E_{\mathrm{c}} / \mathrm{d} \mathrm{pH}=-(2 / 5) 2.303 R T / F
\end{aligned}
$$

At a lower chloride concentration ( $1 \mathrm{M}$ ), deviations occur (especially from the latter relationship) mainly because of the chloride concentration affecting the anodic dissolution reaction.

The anodic dissolution reaction is found to be independent of the $\mathrm{pH}$ and of it occurring together with a simultaneous hydrogen evolution reaction. In strong chloride solutions, it has a Tafel slope of approximately $2.303 R T / 2 F$.

The hydrogen evolution reaction is found to be strongly stimulated by a simultaneously occuring dissolution reaction. When occuring essentially alone, it is first order in hydrogen ion dependence and has a Tafel slope of approximately $-2.303 \times 2 R T / F$ and a standard exchange current (extrapolated) of about $3 \times 10^{-10} \mathrm{~A} / \mathrm{cm}^{2}$.

\subsection{INTRODUCTION}

$\mathrm{T}$ is well known that zinc in acid solution dissolves by a hydrogen evolu1 tion type of attack, and that this process is strongly affected by the $\mathrm{pH}^{1-4}$. Recent investigations on zinc in sulphuric acid solutions ${ }^{5,6}$ have shown its corrosion rate $\left(i_{\mathrm{c}}\right)$ and corrosion potential $\left(E_{\mathrm{c}}\right)$ to vary with $\mathrm{pH}$ approximately as given by:

$$
\begin{aligned}
& \text { 'd } \log i_{\mathrm{c}} / \mathrm{d} \mathrm{pH}=-4 / 5 \\
& \text { d } E_{\mathrm{c}} / \mathrm{d} \mathrm{pH}=-(2 / 5) 2.303 R T / F \mid
\end{aligned}
$$

A main object of the present work is to see if this also is true in hydrochloric acid solutions.

The relationships shown by (1) and (2) are what to be expected on the basis of the theory of mixed potentials ${ }^{7}$ when:

(a) the hydrogen evolution reaction is first order in hydrogen ion dependence and has a Tafel slope of $-2.303 \times 2 R T / F$, 
(b) the anodic dissolution reaction is $\mathrm{pH}$-independent and has a Tafel slope of $2.303 R T / 2 F$, and

(c) no interaction - except for the electron balancing - exists between the two different electrode reactions when occuring simultaneously and at equivalent rates on the same metal surface, or an interaction exists which affects the corrosion by the same rate factor and the same potential difference at all $\mathrm{pH}$-values.

This is not only an arbitrary combination of properties suggested to satisfy (1) and (2), but is partly based on direct knowledge of the single electrode reactions.

What is said under $(a)$ is in agreement with direct results in sulphuric acid solution ${ }^{5,6,8}$, in hydrochloric acid solution ${ }^{8,9}$, and in perchloric acid solution ${ }^{9}$.

What is said under $(b)$ has - to the authors knowledge - direct support only as far as the Tafel slope is concerned ${ }^{10}$. Another object of the present work, therefore, is to elucidate the possible effect of $\mathrm{pH}$ on the anodic dissolution reaction.

What is said under $(c)$ leaves two possibilities, either the existence or the non-existence of an interaction of the mentioned type. Results by Vonwiller ${ }^{8}$ show the former to be true in both sulphuric and hydrochloric acid solutions. For sulphuric acid solutions, this has some support in the cathodic polarization curves given by Rotinyan et $a l .^{5,6}$ The results by Bicelli and Graziano ${ }^{9}$ for zinc in hydrochloric and perchloric acid solutions, however, do not show this so clearly. A further elucidation of this matter is a third object of the present work.

\subsection{EXPERIMENTAL}

The materials used in the present experiments have been the same as previously described ${ }^{10}$. This also applies to the pretreatment of the zinc electrodes (etched for 15 $\min$ in $1 \mathrm{~N}$ hydrochloric acid).

The experiments have been performed in a thermostated room at about $20^{\circ} \mathrm{C}$, partly by cell previously described 11 (both corrosion experiments and galvanostatic polarization experiments) and partly by simple immersion as previously described ${ }^{12}$ (except for the quartz helix measurements there described having been replaced by determinations of the weight loss over various periods of immersion). The saturated calomel electrodes used have been ascribed a potential of $0.245 \mathrm{~V}$ on the normal hydrogen scale (NHS). No attempts have been made to correct for possible liquid junction potentials.

Experiments have been performed with two series of solutions:

$$
\begin{aligned}
& \mathrm{HCl}(x \mathrm{M})+\mathrm{KCl} \quad(\mathbf{l}-x \mathrm{M}) \\
& \mathrm{HCl}(x \mathrm{M})+\mathrm{KCl} \quad(3-x \mathrm{M})
\end{aligned}
$$

in which the total chloride content is constant at 1 and $3 \mathrm{M}$, respectively. The hydrochloric acid molality $(x)$ has been varied from 0.01 to $1 \mathrm{M}$. A solution of $0.05 \mathrm{M}$ sulphuric acid + $1 \mathrm{M}$ potassium chloride has also been used and may be regarded as belonging to the former of the above series.

\subsection{RESULTS}

Fig. 1 shows some examples of corrosion rate curves obtained. These curves apply to various hydrochloric acid molalities in the $3 \mathrm{M}$ chloride series, and each experimental point represents the average of at least four experi-

Acta Chem. Scand. 16 (1962) No. 6 


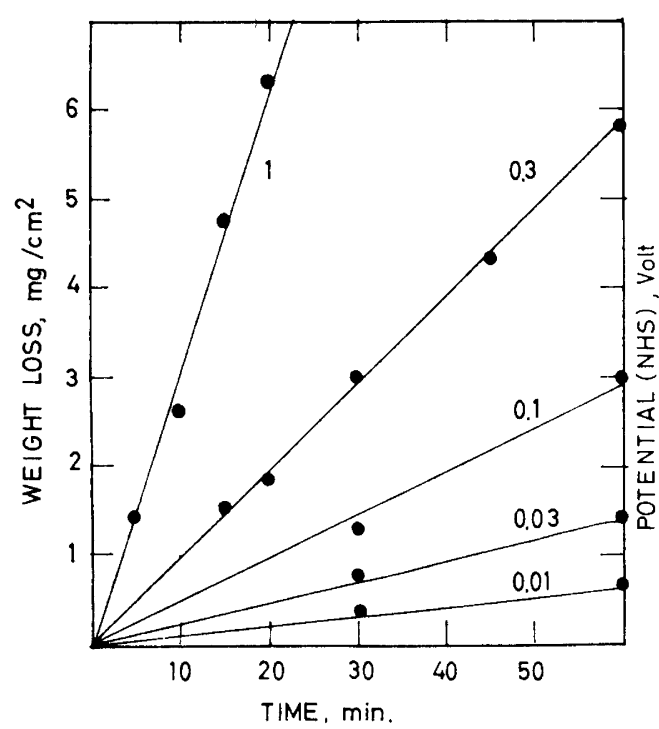

Fig. 1. Weight loss of zinc as function of time in $x \mathrm{M}$ hydrochloric acid $+(3-x) \mathrm{M}$ potassium chloride at $20^{\circ} \mathrm{C}(x=1,0.3,0.1$ 0.03 , and 0.01$)$.

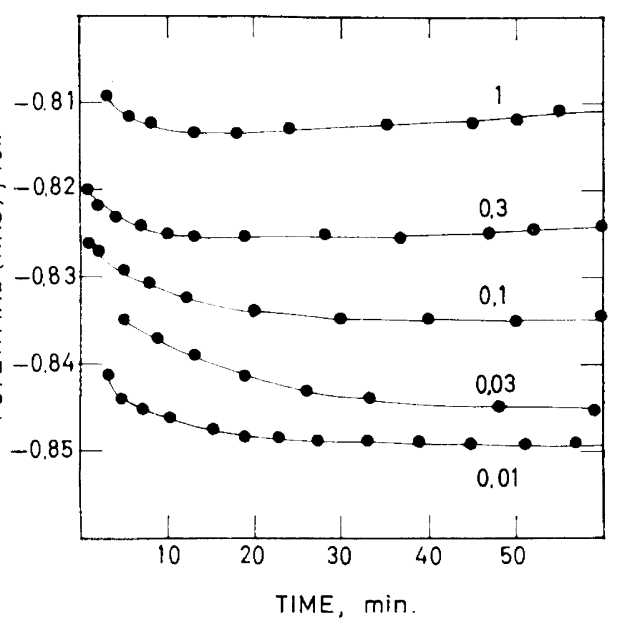

Fig. 2. Corrosion potential of zinc as function of time in $x \mathrm{M}$ hydrochloric acid + $(3-x) \mathrm{M}$ potassium chloride at $20^{\circ} \mathrm{C}(x=1$, $0.3,0.1,0.03$, and 0.01$)$.

ments. The reproducibility, especially in the most acid solutions, was not always the best, the mean deviation sometimes being as bad as $\pm 20 \%$. Analogous results were obtained for the $1 \mathrm{M}$ chloride series, and these combine with those in Fig. 1 in showing the corrosion rate to be essentially constant with time and to increase with the acidity of the solution. The latter is further considered below.

Fig. 2 shows examples of time curves obtained for the corrosion potential at various hydrochloric acid molalities in the $3 \mathrm{M}$ chloride solutions. These curves are representative also for the type of curves obtained in the $1 \mathrm{M}$ chloride solutions. The essentially stationary potential shown by these curves after an initial transient, has generally been well reproducible and is here accepted as the representative corrosion potential.

In Fig. 3, the values thus obtained for the corrosion rate and the corrosion potential of zinc in the mixed $\mathrm{HCl} / \mathrm{KCl}$ solutions applied are plotted versus the hydrochloric acid molality, which, both for the $1 \mathrm{M}$ and the $3 \mathrm{M}$ chloride series, is nearly proportional to the hydrogen ion activity ${ }^{13}$. The corrosion rate is given in current density values which have been calculated from the weight loss data on the basis of the dissolution going to the divalent state ${ }^{10}$. The fully drawn straight lines in Fig. 3 have been given slopes according to (1) and (2), and it may seem that these relationships are not far from being obeyed in the $3 \mathrm{M}$ chloride solutions. In the $1 \mathrm{M}$ chloride solutions, however, the corrosion potential deviates clearly from the relationship (2) by showing a distinctly lower $\mathrm{pH}$-dependence. It is further interesting to note that equal hydrochloric 


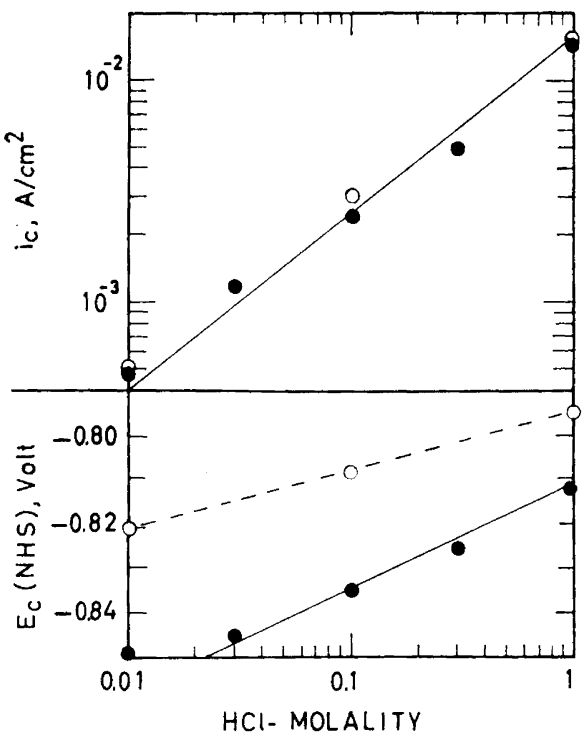

Fig. 3. Corrosion rate $\left(i_{\mathrm{c}}\right)$ and corrosion potential $\left(E_{\mathrm{c}}\right)$ of zinc as functions of hydrochloric acid molality in $\mathrm{HCl} / \mathrm{KCl}$-solutions of total molality 1 (open circles) and 3 (closed circles). $20^{\circ} \mathrm{C}$.

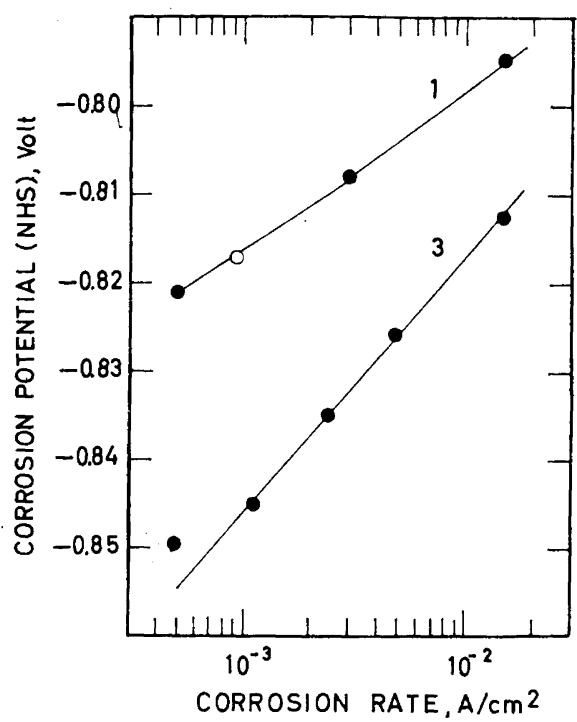

Fig. 4. Corrosion potential versus corrosion rate of zinc in $\mathrm{HCl} / \mathrm{KCl}$-solutions of total molality 1 and 3 . The open circle applies to $0.1 \mathrm{~N}$ sulphuric acid $+1 \mathrm{M}$ potassium chloride. $20^{\circ} \mathrm{C}$.

acid molalities give almost equal dissolution rates, but distinctly different corrosion potentials at the two different total chloride molalities. The latter is in accordance with what is previously found for the effect of the chloride concentration on the anodic dissolution reaction ${ }^{10}$.

In Fig. 4, corresponding values of the corrosion potential and the corrosion rate are plotted versus each other in a Tafel diagram. The Tafel line there drawn for the $3 \mathrm{M}$ chloride series has the same slope $(29 \mathrm{mV})$ and nearly the same position as the one previously determined for the activation controlled anodic dissolution of zinc in less acid solutions of the same chloride content ${ }^{10}$. The curve drawn for the $1 \mathrm{M}$ chloride series also compares well with the anodic polarization curve previously found at this chloride concentration ${ }^{10}$. This obviously means that the anodic dissolution reaction neither is $\mathrm{pH}$-dependent, nor is directly affected by being balanced by a simultaneous hydrogen evolution at the same metal surface (except for the reducing influence the gas stirring has on the anodic concentration polarization found to be present in unstirred solutions ${ }^{10}$ ).

In Fig. 5, results obtained for the dissolution reaction and the hydrogen evolution reaction from experiments with galvanostatically applied currents in a $1 \mathrm{M}$ and $3 \mathrm{M}$ chloride solution of $0.1 \mathrm{M}$ hydrochloric acid, are given in the form of a Tafel diagram plot. The rate of the dissolution reaction has been determined from the weight loss of the zinc electrodes with corrections for 


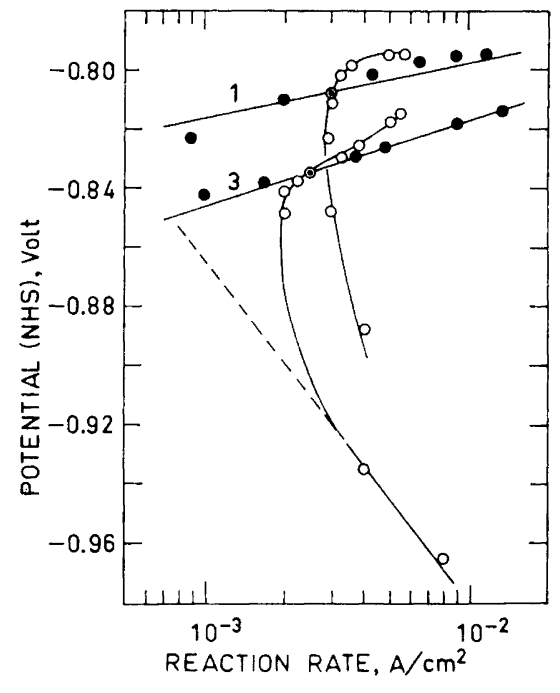

Fig. 5. Tafel diagram for anodic dissolution of zinc (closed circles) and hydrogen evolution on zinc (open circles) in $0.1 \mathrm{M}$ hydrochloric acid solutions of potassium chloride at total molalities of 1 and 3 . Corrosion points are given by centred circles. $20^{\circ} \mathrm{C}$.

the corrosion occurring in the cell prior to application of current. The rate of the hydrogen evolution reaction has been determined from the same weight loss data by adding (resp. subtracting) the rate corresponding to the cathodic (resp. anodic) current applied in the various cases.

The anodic polarization curves drawn in Fig. 5 have been reproduced from the corrosion curves in Fig. 4. The reasonable fit of the experimental points to these lines is a further verification of the anodic dissolution reaction being essentially independent of the $\mathrm{pH}$ and of it occuring simultaneously with a hydrogen evolution reaction on the same metal surfaces.

The polarization data given for the hydrogen evolution reaction in Fig. 5 show this reaction to be strongly stimulated by a simultaneously occurring zinc dissolution reaction, as previously found by Vonwiller ${ }^{8}$. This stimulation is similar to the one previously observed also for hydrogen evolution on iron ${ }^{11}$, but appears stronger, especially at and below the corrosion point (the corrosion point being given by centred circles in Fig. 5). Only at potentials low enough to make the dissolution reaction negligibly slow, does the hydrogen evolution reaction seem to follow the Tafel relationship. This is indicated by the partly dashed line in Fig. 5, which have been drawn with a Tafel slope of - $116 \mathrm{mV}$ $($ i.e. $-2.303 \times 2 R T / F)$. Both the slope and the position of this line is in reasonable agreement with previous results $5,6,8,9$ when the comparison is based on the reaction being first order in hydrogen ion dependence. Assuming the suggested Tafel slope and the first order hydrogen ion dependence to be correct, the present results indicate a standard exchange current of about $3 \times 10^{-10} \mathrm{~A} / \mathrm{cm}^{2}$ for the hydrogen electrode on zinc (in the hypothetical absence of zinc dissolution or of any effect of this dissolution). This is very much lower than the analogous value of about $4 \times 10^{-6} \mathrm{~A} / \mathrm{cm}^{2}$ previously found for the hydrogen electrode on iron ${ }^{11}$. 


\subsection{DISCUSSION}

The present results show that the corrosion of zinc in acid chloride solutions is affected not only by the $\mathrm{pH}$, but also by the salt content of the solutions (see Fig. 3). The salt content mainly affects the corrosion potential, and this seems mainly due to it having a greater effect on the relatively weakly polarizing anodic dissolution reaction than on the more strongly polarizing hydrogen evolution reaction (see Figs. 4 and 5), and to these two effects partly being rate compensating (see Fig. 5). The effect here observed of the salt content on the anodic dissolution reaction is in agreement with previous results ${ }^{10}$, but no clear understanding of it has been obtained. For the hydrogen evolution reaction, the observations may indicate the salt effect to be an indirect one, possibly resulting from the influence of the salt content on the anodic dissolution reaction and its interaction with the hydrogen evolution reaction. Because of the salt effect and the mentioned interaction, it is no wonder that the pH-relationships (1) and (2) in the introduction to this paper are not always obeyed by zinc in acid chloride solutions. It is important, however, that reasonable obedience to these relationships is found in strong chloride solutions of constant chloride content ( $3 \mathrm{M}$ ).

The present results give some support for the hydrogen evolution reaction on zinc (when occurring essentially alone on the zinc surface) obeying the Tafel relationship with a slope of $-2.303 \times 2 R T / F$, and for it being first order in hydrogen ion dependence (the latter especially by comparing with previous results). They further clearly show that the anodic dissolution reaction is $\mathrm{pH}$ independent, that it to some extent is affected by the salt content of the solution, and that it in strong chloride solutions (3 M) obeys the Tafel relationship with a slope of $2.303 R T / 2 F$. The latter two findings are in agreement with previous results ${ }^{10}$.

The perhaps most interesting results obtained are those showing the presence of a strong, stimulating interaction of the zinc dissolution reaction with the hydrogen evolution reaction when these occur simultaneously on the same metal surface. As shown in Fig. 5, the stimulation caused by this interaction at a given $\mathrm{pH}$ increases with the rate of the anodic dissolution reaction. It even increases so strongly that a reversal occurs in the apparent potential dependence of the hydrogen evolution reaction. At the highest anodic dissolution rates (or most anodic potentials) in Fig. 5, the hydrogen evolution reaction is more than ten times as fast as one should expect from the suggested "interaction free" cathodic Tafel line. From the same diagram is further seen that the corrosion rate is four to five times as high as one should expect in the hypothetical case of no interaction. As further the corrosion rate is found to vary with $\mathrm{pH}$ in accordance with (2), one must assume the "stimulation factor" at the corrosion potential to be nearly independent of the $\mathrm{pH}$ and, thereby, of the corrosion rate. This may perhaps indicate the stimulation to be more determined by the relationship between the rates of the two simultaneously occuring reactions than by the rate of the dissolution reaction alone.

A quite similar non-mutual interaction between a metal dissolution reaction and a simultaneous hydrogen evolution reaction as here found for zinc, has previously been found also for iron ${ }^{11}$. No clear understanding of this interac-

Acta Chem. Scand. 16 (1962) No. 6 
tion has been obtained, but it may be that the dissolution reaction, when in act of occurring, creates favourable reaction sites for the hydrogen evolution reaction or in other ways facilitates this reaction.

Acknowledgement. The author is much indebted to Miss T. Tönderum and Miss K. Storström for technical assistance, to various members of the staff at the Central Institute for Industrial Research for helpful discussions, and to the U.S. Department of Army, European Research Office, for financial support.

\section{REFERENCES}

1. Anderson, E. A. and Reinhard, C. E. in Uhlig, H. H. (Ed.) Corrosion Handbook, Wiley, New York 1948, p. 331.

2. Evans, U. R. The Corrosion and Oxidation of Metals, Arnold, London 1960, pp. 310-11 and 317-19.

3. Katz, W. in Tödt, F. (Ed.) Korrosion und Korrosionsschutz, de Gruyter, Berlin, 2nd ed. 1961, p. 198.

4. Marcovic, T., Dugi, Z. and Rubinic, Lj. Werkstoffe u. Korrosion 9 (1958) 17.

5. Rotinyan, A. L., Fedot'ev, N. P. and Sok, L. U. Zhur. Fiz. Khim.31 (1957) 1295.

6. Sok, L. U., Rotinyan, A. L. and Fedot'ev, N. P. Zhur. Fiz. Khim.32 (1958) 2514.

7. Vetter, K. J. Elektrochemische Kinetik, Springer, Berlin/Göttingen/Heidelberg 1961, pp. $588-602$.

8. Vonwiller, W. Auflösungsvorgänge und Wasserstoff-Abscheidung an Zink-Elektroden, Prom. Nr. 2448, Eidg. Techn. Hochschule, Zürich 1955.

9. Bicelli, L. P. and Graziano, M. Research on Hydrogen Overvoltage on Metallic Single Crystals: Zinc, Technical Note No. 6, Contract AF 61(052)-44, U.S. Air Force, European Research Office, Brussels, February 1961.

10. Hurlen, T. Acta Chem. Scand. 16 (1962) 1337.

11. Hurlen, T. Acta Chem. Scand. 14 (1960) 1533.

12. Hurlen, T. Acta Chem. Scand. 15 (1961) 615.

13. Harned, H. S. and Gancy, A. B. J. Phys. Chem. 62 (1958) 627.

Received December 22, 1961. 